Article

\title{
Student Engagement for Sustainability of Chinese International Education: The Case of International Undergraduate Students in China
}

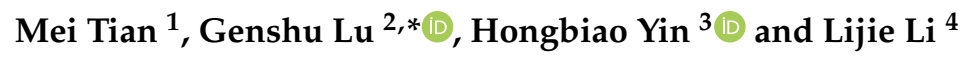 \\ 1 School of Foreign Studies, Xi'an Jiaotong University, Xi'an 710049, China; temmytian@mail.xjtu.edu.cn \\ 2 West China Higher Education Evaluation Centre \& Institute of Higher Education, Xi'an Jiaotong University, \\ Xi'an 710049, China \\ 3 Faculty of Education, The Chinese University of Hong Kong, Hong Kong SAR., China; yinhb@cuhk.edu.hk \\ 4 School of Public Policy and Administration, Xi'an Jiaotong University, Xi'an 710049, China; \\ lilijie@stu.xjtu.edu.cn \\ * Correspondence: gslu@mail.xjtu.edu.cn
}

Received: 1 August 2020; Accepted: 21 August 2020; Published: 23 August 2020

\begin{abstract}
Student engagement has been attracting attention in the discussion of higher education (HE) quality. Despite the rapid increase of international students in China, little understanding has been gained for quality management on these students' engagement in learning. This paper focuses on international undergraduate students in Chinese higher education institutions, exploring the nature and characteristics of their academic engagement and the environmental factors influencing the engagement. The discussion was based on a synthesis of the findings of two studies, i.e., an exploratory qualitative study following a small group of international students at a research university and a large-scale survey involving 1428 international students at 34 Chinese universities. The analyses revealed less than satisfactory levels of international students' engagement, with a high proportion of the participants being passively or ineffectively involved in learning. The qualitative findings highlighted pedagogical and attitudinal factors that affected international students' engagement. The survey results indicated six environmental factors, categorized into three groups, having significant effects on the respondents' engagement. Although located in China, the analyses bear implications for practitioners striving for the sustainable development of international education in a broader range of contexts.
\end{abstract}

Keywords: international student education; China; student engagement; environmental influences

\section{Introduction}

The new century is witnessing the dramatically rising phenomenon of internationalization of Chinese universities. Being probably the most visible representation of internationalization, international students have been an increasingly significant proportion of the student population in Chinese higher education (HE). In 2018, 492,185 international students studied at 1004 higher education institutions (HEIs) in China [1], making the country the third most popular international student destination country in the world [2]. It has been estimated that China will replace the United Kingdom as the second-largest destination country for international students after the United States only [3].

Nevertheless, there is a lack of understanding of international students' academic engagement during their studies in China [4]. Worldwide student engagement has become a buzzword in the discussion of HE quality. It is argued that for effectively formulating and implementing policies to improve student learning, the government and HEIs need to understand how students mobilize university resources and devote themselves to meaningful educational practices [5]. Despite the 
recent expansion of international student enrollment in China, there are few international publications on these students' academic engagement. Although the growing research has contributed to the understandings of international students' choice of China for education [6-8], intercultural adaptation and identity [9], and levels of satisfaction [6,10], very little generalizable data have been gained for the purpose of quality management on their engagement in learning in Chinese HEIs.

This article focuses on international undergraduate students' engagement with Chinese higher education. The investigation is based on the findings of two studies. The first study is exploratory qualitative research probing from a holistic perspective into a small group of medical students' learning experiences. The second study is survey research designed based on the first study, involving 1428 international undergraduate students at 34 Chinese universities. Drawing on the data generated by the survey study, complemented by the findings of the exploratory qualitative research, this article discusses international undergraduate students' engagement in educational practices and the effectiveness of Chinese institutions stimulating such engagement. Although focusing on China, the analyses hold implications for the sustainable development of international education in a broader range of contexts.

In what follows we first review the recent expansion of international student enrollment in China. We then review the literature on student engagement and environmental factors affecting student engagement. The article then presents research methodology and findings, followed by a discussion of the findings and the implications.

\section{China Context: International Student Expansion and Quality Concerns}

China has long been a major source country of international students worldwide. The new century sees China rising as a leading destination country for international students [11]. In 1992, roughly 12,000 international students studied in China; this number expanded to 44,711 in 1999 [12]. Since 2000, with the rapid development of the country's higher education, China has increased its attractiveness among international students. In the first decade of the century, the number of inward international students in China kept growing from 61,869 in 2000 to 238,184 in 2009. The release of the Study of China Scheme in 2010 marked international student recruitment starting to be pursued as a national strategic initiative [13]. With government promotion, between 2010 and 2018, the number of inward international students in China increased by roughly 5\% annually, reaching 492,185 in 2018 [1,14]. Figure 1 displays the numbers of inward international students in China in recent decades [1,14-30].

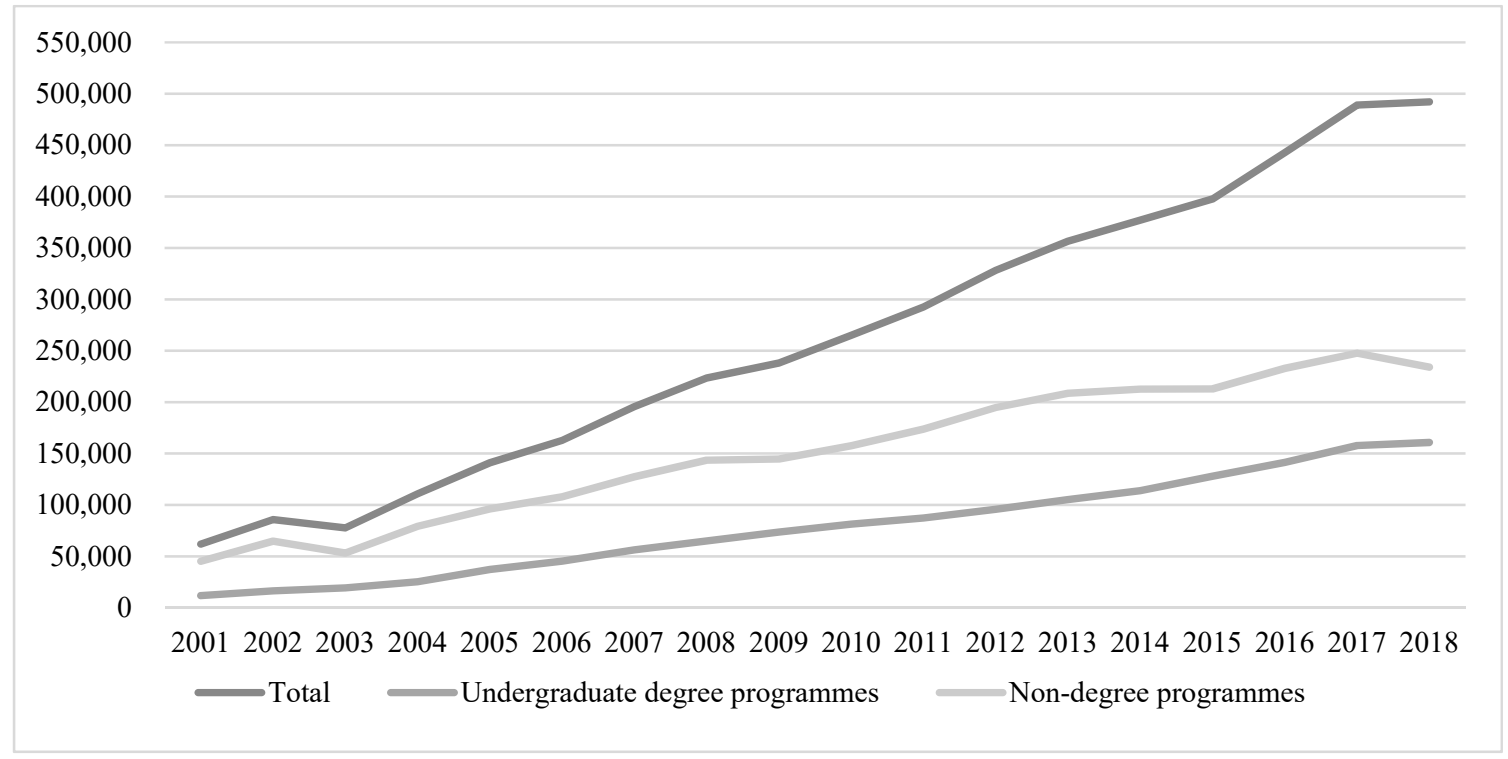

Figure 1. International student expansion in China [1,14-30]. 
As shown in Figure 1, a high proportion of inward international students are in non-degree programs, challenging the validity of China's high positioning as the third-largest international student destination. For those registered in degree-bearing programs, medicine has long been the most popular major. The medical undergraduate programs, known as the Bachelor of Medicine and Bachelor of Surgery (MBBS), were among the first English-medium undergraduate programs that Chinese universities offered to international students. Over the recent decade, the engineering discipline has become the most fast-growing major for international students in China, transforming from the $10^{\text {th }}$ most popular discipline in 2010 [14] to the $2^{\text {nd }}$ in 2018, following medicine only [1]. Behind the rapid increase of international engineering students is the enhanced academic strength of the engineering discipline, particularly at the national elite "double-first-class" universities [31-34]. The "double-first-class" initiative guarantees generous financial investment to selected universities and disciplines to reach international academic excellence. In support of China's building the innovation-driven economy, the "double-first-class" initiative favors science and engineering disciplines [35].

Nevertheless, the rapid expansion of inward international students in China raises concerns over the quality of education these students receive. Aware of the growing concerns, in 2018, the MoE issued the "Quality Standards for International Student Higher Education in China (trial version)" (hereafter the Standards) [36], marking the development of Chinese international education into an era of "quality and efficiency" [37]. This very first national policy on quality management for international degree programs focuses on the macro-level of educational standards, concerning faculty qualification, resources, equipment, and facilities. To better monitor micro-level teaching and course administration, more research that focuses on international students' perceptions of their engagement in learning is urgently required.

\section{Student Engagement and HE Quality Assurance}

Student engagement is currently the focus in discussions of HE quality assurance, following "course management" and "teaching quality" [38]. This focus on students in quality evaluation has drawn on the earlier work by Pace [39], Astin [40], and Tinto [41]. Tinto's [41] work on the contribution of social and academic integration to student persistence, in particular, highlights the significance of student involvement, which Tinto acknowledged has similar meanings with engagement. Krause and Coates [42] note that since ensuring students' good learnings is a fundamental function of HEIs, assessing student engagement is crucial to inform HE practices, policies, and quality control.

One widely cited definition of student engagement is given by Hu and Kuh [43], who interpret student engagement as the "quality of effort students themselves devote to educational purposeful activities that contribute to desired outcomes" (p.555). Developing the National Survey of Student Engagement with his colleagues, Kuh [44] proposes that engagement could be quantitatively assessed along the following five dimensions, i.e., active and collaborative learning, levels of academic challenge, student-faculty interaction, enriching educational experiences, and supportive campus environment. Other researchers argue that student engagement is multifaceted, involving behavior, emotional, and cognitive dimensions [45], and thus qualitative research holistically exploring students' perceptions toward engagement is of importance. Following Kuh's interpretation of student engagement, a large volume of engagement research has been published. The findings suggested a close linkage between student engagement and positive outcomes of learning, such as retention [46], critical thinking abilities [47], and satisfaction [48]. This research, documenting student learning through students' perceptions and voices [49], supports the HE faculty and institutions to review and diagnose weaknesses in practices and design and implement measures for improvement [50].

In China, the academic discussion on HE quality has long been focused on the review of international literature and its implications for Chinese practices. The recent introduction of Kuh's student survey to China, which presents empirical evidence of student learning, has triggered extensive interests among Chinese HEIs facing competitions for funding and pressure for public accountability [51]. For example, a survey study [52] found that compared to their peers at 
American universities, Chinese undergraduate students showed lower levels of engagement in student-faculty interaction and meeting academic challenges. Another survey [53] reported that more than half of the Chinese undergraduate participants were either "motivated but less-engaged" or "maladaptive/disengaged" in learning. It should be noted that despite its well-recognized significance in Chinese HE evaluation, the existing engagement research focused on Chinese domestic students only. There exists no large-scale engagement survey involving international students in Chinese HEIs or adequate qualitative studies illuminating international students' perceptions of academic engagement during their studies in China. Chinese universities are becoming growingly internationally engaged; this changing nature of HEIs needs to be addressed in research to ensure their sustainable provision of quality education for domestic and international students alike.

\section{Environmental Factors Influencing Student Engagement}

Following Lim and Fraser [54], this article defines learning environments as in-class and on-campus social and pedagogical contexts, in which students' learning takes place. Scholars have argued for the linkage between the learning environment and student engagement. Kahu [38], for example, by proposing an integrated framework of student engagement, antecedents, and consequences, stresses student engagement is not "an internal static state" (p.766) but is instead embedded in sociocultural contexts. Coates [55] argues that although individual learners are ultimately responsible for engagement, the discussion of engagement should not be limited to the individual student level; rather, the importance of learning contexts should be acknowledged. Empirical evidence has shown that a positive learning environment supports and stimulates students' participation in educational practices. For example, student engagement can be encouraged by teacher support [56], innovative instructional methods [57], collaborative learning activities [58], academically challenging curricula [59], course-related teacher-student interactions [59], and informal learning space outside classes [60].

Other researchers suggest that student engagement differs by disciplines [38] and that institutions support student engagement through ensuring well-organized courses and appropriate learning opportunities [49]. A case study of a midwestern US university showed that students in arts, humanities, and social sciences were more engaged in interactive learning due to the communicative nature of these disciplines [57]. In contrast, Brint, Cantwell, and Saxena [61] reported that at US research universities students in sciences and engineering spent longer hours on study due to the disciplines' quantitatively challenging content [62], stringent grading practices [63], and expectations of higher monetary returns in job market [64]. In China, a case study of Tsinghua University showed that undergraduates in industrial engineering reported much higher engagement in extracurricular studies with the school's stress on challenging course content [65]. It was also reported that undergraduate students at Chinese elite research universities were generally more engaged in learning than their peers at teaching-centered universities [66], leading to a conclusion that the elite research universities in China, with generous national funding to reach academic excellence, could better support their students' academic engagement [53].

The body of work on international students in traditional destination countries (i.e., the United States, the United Kingdom, Canada, and Australia), though usually not flagged with "student engagement", has also revealed a significant relationship between learning contexts and student engagement. For example, studies have shown that group work, class discussion, and writing assignments provide chances for international students' cross-cultural learning through meaningful interactions with teachers and domestic students [67-69]. Academics, through carefully designing and managing co-operative learning activities, can encourage and support international students' academic engagement [70,71]. It is also found that the incomprehensibility of teaching content, traditional teaching methods, and lack of teachers' support are more likely to challenge non-native-English-speaking international students, turning many of them into learners with an independent style of engagement, i.e., holding an academically but less socially oriented approach in learning [55,72]. It is worth noting 
that a negative campus atmosphere, such as the unequal power relationship between students and academics [73], and a lack of respect for diversity and differences [38] can result in international students' disengagement with higher education [72].

\section{The Studies}

Study 1 was a small-scale longitudinal study (2011-2016) functioning as a pilot for Study 2. The study followed a small group of inward international students through their undergraduate studies in MBBS at a national elite double-first-class university in China. The MBBS program was chosen as a focus in the given study due to its long history of recruiting international students, and it remains the most popular discipline for international undergraduate students choosing to study in China.

Primary data sources were annual interviews, investigating their educational experiences in China. The interviews took different forms, with two rounds of semi-structured interviews at the beginning and end of the degree course and un-structured interviews in-between. Each interview lasted around 1.5 hours. Interview participants included four female and four male students from six different countries (i.e., Pakistan, Malaysia, Canada, Tanzania, Zambia, and Zimbabwe). The interview sample size allowed few generalizable conclusions, but from the unstructured, narrative interviews emerged the significance of students' academic engagement in their evaluation of the degree education. For the purpose of this article, the interview findings related to academic engagement were selected and briefly discussed from the general findings. These findings complemented those of Study 2, helping us understand the nature and characteristics of international undergraduate student engagement and how their engagement was affected by a range of contextual factors.

Study 2 was designed, on the basis of Study 1, to investigate inward international undergraduate students' academic engagement on a much larger scale. The quantitative survey used the student engagement scale of the Student Experience at Research University-International (SERU-I) developed by the University of California at Berkeley to measure the survey respondents' academic engagement [74]. The survey adopted two sub-scales of the SERU-I campus climate scale and six sub-scales of the self-developed University Mathematics Classroom Experience Questionnaire (UMCEQ) [75] to explore the influences of learning environments on student engagement. Necessary changes were made to adapt the scales to the survey study, including modifying the original items to fit the participant sample with board national and disciplinary backgrounds. The original UMCEQ items were translated from Chinese into English and cross-checked by a native-English-speaking researcher. The survey was piloted with 25 senior international students at the double-first-class university where Study 1 had been conducted. Based on these students' responses, the expressions used within the survey questionnaire were further modified, clarified, or simplified. Table 1 presents the results of confirmatory factor analysis, confirming the construct validity of the survey's factor structures.

Table 1. Construct validity.

\begin{tabular}{ccccccc}
\hline Scale & $\chi \mathbf{2}$ & $d f$ & $\boldsymbol{P}$ & RMSEA & CFI & TLI \\
\hline Student engagement & 2412.894 & 269 & $P<0.001$ & 0.075 & 0.889 & 0.876 \\
Classroom learning & 5246.248 & 830 & $P<0.001$ & 0.061 & 0.908 & 0.899 \\
environment & 764.099 & 64 & $P<0.001$ & 0.088 & 0.949 & 0.938 \\
Campus climate &
\end{tabular}

Note: $\overline{R M S E A}=$ root mean square error of approximation, CFI = comparative fit index, TLI = Tucker Lewis index.

In 2016, 3709 copies of the paper-based questionnaire were randomly distributed to international undergraduate students at 34 full-time Chinese public universities. The study involved participants in various disciplines, with the majority studying life sciences and medicine. The high proportion of medicine-major participants documented within this majority was in line with the popularity of MBBS among the international student population in China. The participating universities are located in central, eastern, and western China, of which 17 are double-first-class research-oriented universities, and another 17 are non-double-first-class teaching-oriented universities. The international offices 
or the schools of international students in the participating universities approved the content of the questionnaire and provided access to potential participants. The paper questionnaire was anonymous and most participants completed the questionnaire within 45 minutes. The survey resulted in 1428 $(38.9 \%)$ responses. Table 2 presents the respondent profile. Table 2 presents the respondent profile.

Table 2. Participant profiles.

\begin{tabular}{lcc}
\hline \multicolumn{1}{c}{ Category } & Frequency & $\%$ \\
\hline Gender & 750 & \\
Male & 663 & 52.5 \\
Female & 15 & 46.4 \\
Missing & 1428 & 1.1 \\
Total & & 100.0 \\
Continent & 999 & \\
Asia & 321 & 70.0 \\
Africa & 85 & 22.5 \\
Other (Europe, America, and Oceania) & 23 & 6.0 \\
Missing & 1428 & 1.6 \\
Total & & 100.0 \\
Discipline & 281 & \\
Arts, Humanities, and Social Sciences & 147 & 19.7 \\
Sciences and Engineering & 965 & 10.3 \\
Life sciences and medicine & 35 & 67.6 \\
Missing & 1428 & 2.4 \\
Total & & 100.0 \\
Institution & 445 & \\
Double-first-class university & 983 & 31.2 \\
Non-double-first-class university & 1428 & 68.8 \\
Total & & 100.0 \\
\hline
\end{tabular}

\section{Findings}

\subsection{Study 1: Exploratory Qualitative Research}

Study 1 explored the overall experiences of a small group of international medical students at a national key research-centered university. The unstructured, narrative interviews revealed that compared to the off-campus sociocultural experiences, it was the participants' on-course learning experiences that attracted much of their dissatisfaction. For the purpose of this article, we sketch the participants' comments on learning experiences, which has a strong focus on their academic engagement:

1. Participants reported that host teachers were knowledgeable but failed to adequately deliver their knowledge to students. Much criticism was on traditional, didactic lecturing and that teacher was the only dominant figure in classrooms, tending to cram in the information. Participants reported that they interacted with teachers less often than they had expected or less often than they had been used to interacting with home teachers:

"... in Canada we had to do like group assignments, we had to do lab reports, it was a good mixture. Whereas here it's more like the teacher tells you exactly what he's teaching you and you just listen ..."

2. While all participants reported few teacher-student interactions in class, some found teachers were not approachable outside the class. Most students attributed the lack of teacher-student interaction to the language barrier, reporting that the majority of their teachers had inadequate English proficiency. Some, however, perceived that teachers lacked the willingness to listen to, communicate with, or "include" international students in teaching:

"... I call my teacher. They don't even pick up the phone. Why does that happen? One thing that came to me is that the teachers don't want to see me or they just find it troublesome". (Malaysian student) 
3. With the weak teacher-student interaction, participants stressed the importance of the learning support from other students, particularly more experienced co-national senior students. As one said in his third-year study, " ... many times they [freshmen] come to me for advice, not about Chinese, but general stuff, the medical course" (Pakistani student).

4. Dissatisfied with teaching, one participant reported that going to class was "just for the sake of, you know, attendance" (Pakistani student). Some purchased international textbooks and challenged themselves to learn subject knowledge through self-study. Many adopted the examination-oriented learning approach, studying primarily before examinations. These students were also found to study to meet minimal course requirements, i.e., handing in homework, memorizing what had been crammed in lectures, and passing examinations:

"Back home we don't cram. You understand and you write what you understand... Here, [memorizing lecturers' Power Point] slides, and then exactly the way it is in the slides. Before exam, we need it ... just memorising everything". (Malaysian student)

5. Much severe criticism was on course administrators, whose attitudes were often described as bureaucratic and indifferent. The negative interactions with non-academic staff resulted in frustration and a feeling of being hurt, which in turn affected students' learning:

"I see a problem, I call four times. She [administrator] said, "OK, I'll send someone". She doesn't send anyone". (Tanzanian student)

"... XXX [administrator] used to tell us that we have to come to the office to register this and that. ... We have classes from 8:00 in the morning until 9:00 in the evening. When you skip the class to go to the office, he would come and check attendance, and we are absent. When we explain to him, he is like 'it's not my problem'". (Zimbabwean student)

\subsection{Study 2: Quantitative Survey}

\subsubsection{Descriptive statistics}

Drawing on the findings of Study 1, Study 2 was designed and conducted to investigate the academic engagement of international undergraduate students in Chinese HEIs and the environmental factors influencing their engagement. Study 2, using SPSS 22.0, calculated the means and standard deviations of the participants' responses, which were measured by a 6-point Likert scale from 1 (never/strongly disagree) to 6 (very often/strongly agree).

As shown in Table 3, the respondents rated their academic engagement less positively than their perceived learning environments. The mean scores for the five student engagement factors ranged between 4.87 and 2.92, with the lack of engagement (LE, reverse-coded) scoring the highest and the interaction with faculty (IF) scoring the lowest. The results showed that the respondents almost often attended a class on time or submitted the assignment before deadlines, tended to frequently engage in academic analysis and comprehension, challenging activities, or extracurricular learning, and only tended to sometimes interact with the faculty. The passive engagement and lack of interactions with teachers were in line with the understandings gained from Study 1.

Table 3 also shows that the mean score for the eight classroom environment factors ranged between 4.27 and 3.54, with cooperative learning (CL) scoring the highest, teaching innovation (TI) scoring the second lowest, and learning difficulties (LD) scoring the lowest. The survey results showed that the respondents slightly agreed that students supported each other in subject learning. The respondents only tended to slightly agree that class teaching offered adequate opportunities for autonomous learning, teachers adopted diverse and innovative teaching methods, or teaching content was adequately challenging. The emphasis on cooperative learning, the lack of teaching innovation, and the lack of academic challenges in class teaching were in line with the findings of Study 1. In addition, although the survey respondents rated the general campus atmosphere (GA) more 
positively than classroom environment factors, they slightly agreed that they felt being respected on campus. The results were in accordance with students' perceived lecturers' and course administrators' attitudinal problems that Study 1 identified.

Table 3. Descriptive statistics and reliability.

\begin{tabular}{|c|c|c|c|c|c|c|}
\hline Scale & Factor & $\begin{array}{c}\text { Number } \\
\text { of } \\
\text { Items }\end{array}$ & Example Item & $\alpha$ & Mean & SD \\
\hline \multirow{5}{*}{ SE } & $\mathrm{AU}$ & 9 & $\begin{array}{l}\text { I explained methods, ideas or concepts and } \\
\text { used them to solve problems. }\end{array}$ & 0.919 & 3.57 & 1.09 \\
\hline & MAC & 6 & $\begin{array}{l}\text { I asked insightful questions in class. } \\
\text { I talked with the teachers outside of class }\end{array}$ & 0.856 & 3.52 & 1.13 \\
\hline & IF & 5 & $\begin{array}{l}\text { about issues and concepts instructed } \\
\text { in teaching. }\end{array}$ & 0.847 & 2.92 & 1.13 \\
\hline & $\begin{array}{l}\text { LE } \\
\text { (reverse-coded) }\end{array}$ & 4 & I skipped class. & 0.862 & 4.87 & 1.01 \\
\hline & $\mathrm{EE}$ & 4 & I worked on learning project outside of class. & 0.807 & 3.54 & 1.10 \\
\hline \multirow{8}{*}{ CLE } & TS & 6 & Teachers always try their best to help. & 0.931 & 4.27 & 1.04 \\
\hline & PC & 4 & $\begin{array}{l}\text { My course-mates and I compete with each } \\
\text { other in learning. }\end{array}$ & 0.769 & 4.21 & 0.96 \\
\hline & CL & 6 & $\begin{array}{l}\text { My course-mates and I help each other } \\
\text { in learning. }\end{array}$ & 0.915 & 4.40 & 0.93 \\
\hline & $\mathrm{CO}$ & 5 & The programme is well organised. & 0.918 & 4.00 & 1.05 \\
\hline & $\mathrm{TI}$ & 4 & Teaching methods are diverse and flexible. & 0.896 & 3.92 & 1.10 \\
\hline & SA & 4 & $\begin{array}{l}\text { I have the freedom to choose what I would } \\
\text { like to study. }\end{array}$ & 0.821 & 3.98 & 1.05 \\
\hline & DL & 5 & $\begin{array}{l}\text { It is difficult for me to understand what is } \\
\text { taught in class. }\end{array}$ & 0.889 & 3.54 & 1.08 \\
\hline & IS & 4 & $\begin{array}{l}\text { Teaching has inspired my enthusiasm for } \\
\text { further learning. }\end{array}$ & 0.927 & 4.11 & 0.98 \\
\hline \multirow[b]{2}{*}{$\mathrm{CC}$} & RD & 5 & The campus atmosphere is safe. & 0.932 & 4.15 & 1.00 \\
\hline & GA & 8 & $\begin{array}{l}\text { Students with my ethnic background are } \\
\text { respected on campus. }\end{array}$ & 0.905 & 4.30 & 0.98 \\
\hline
\end{tabular}

Note: 1. $\mathrm{SE}=$ student engagement, $\mathrm{AU}=$ participation for analytical understanding, $\mathrm{MAC}=$ meeting academic challenges, IF = interaction with faculty, LE = Lack of Engagement, EE = extracurricular engagement; 2. $\mathrm{CLE}=$ classroom learning environment, $\mathrm{TS}=$ teacher support, $\mathrm{PC}=$ peer cooperation, $\mathrm{CL}=$ cooperative learning, $\mathrm{CO}=$ course organization, $\mathrm{TI}=$ teaching innovation, $\mathrm{SA}=$ student autonomy, $\mathrm{DL}=$ learning difficulties, $\mathrm{IS}=$ intellectual stimulation; 3 . $\mathrm{CC}=$ campus climate, $\mathrm{RD}=$ respect for diversity, $\mathrm{GA}=$ general campus atmosphere; 4. Each factor score is the mean of all items' scores.

\subsubsection{SEM Analysis}

Study 2 conducted structural equation modeling (SEM) to explore the influences of learning environments on the survey respondents' engagement. Figure 2 presents the standardized regression coefficients for each path that reached a significant level. The results showed that the model fitted statistically well to the data. Its goodness-of-fit indices are: $\chi^{2}=461.533$ ( $\mathrm{df}=38, \mathrm{P}<0.001, \chi^{2}$ can reach a significant level given the big size of sample), RMSEA $=0.088, \mathrm{CFI}=0.960$, and TLI $=0.888$. 


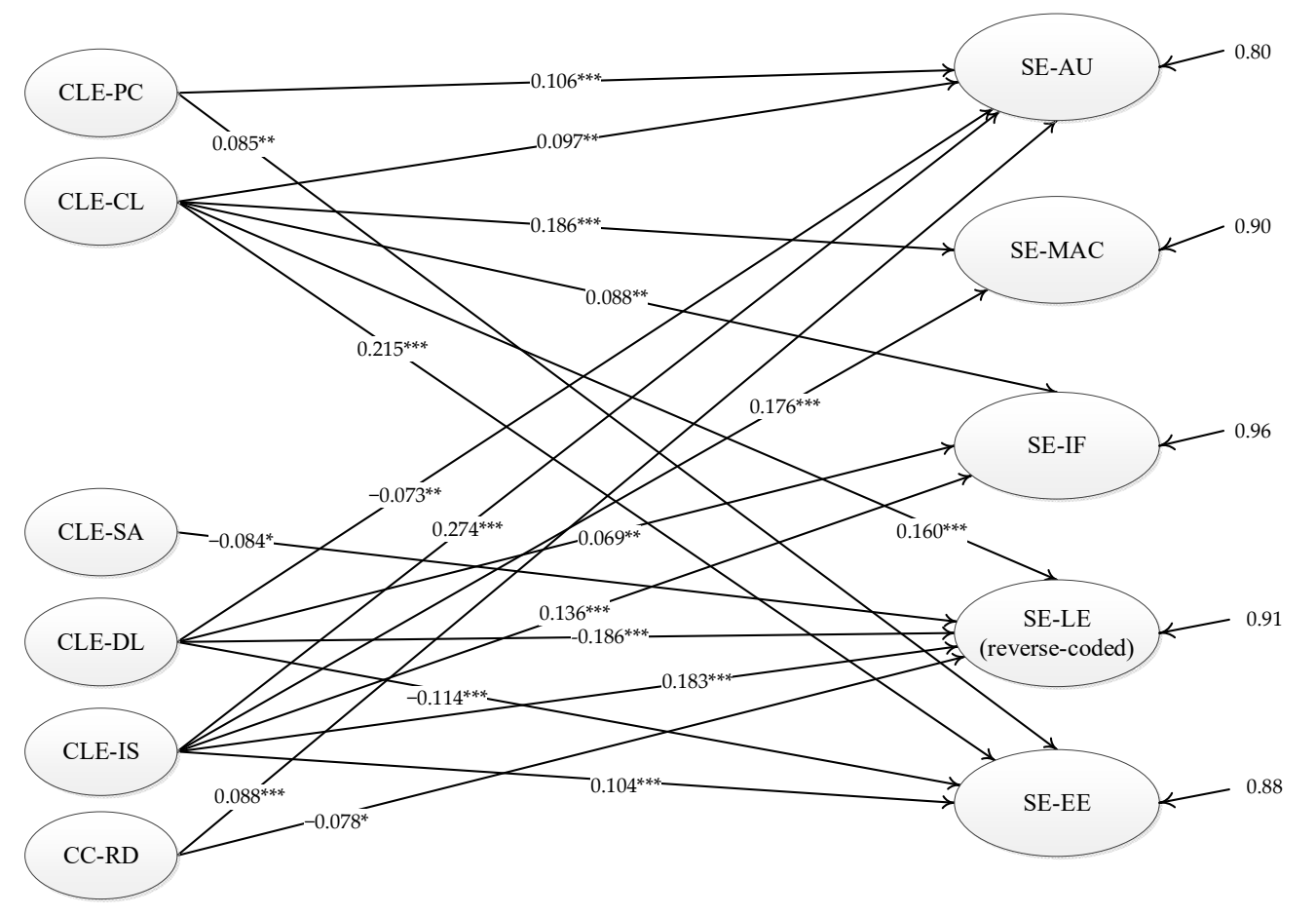

Figure 2. Influences of Perceived Learning Environments on Academic Engagement.

Note: 1. $C L E=$ classroom learning environment,$P C=$ peer cooperation, $C L=$ cooperative learning, $\mathrm{SA}=$ student autonomy, DL = learning difficulties, IS = intellectual stimulation; $2 . \mathrm{CC}=$ campus climate, $\mathrm{RD}=$ respect for diversity; $3 . \mathrm{SE}=$ student engagement, $\mathrm{AU}=$ participation for analytical understanding, $\mathrm{MAC}=$ meeting academic challenges, $\mathrm{IF}=$ interaction with faculty, $\mathrm{LE}=$ lack of engagement, $\mathrm{EE}=$ extracurricular engagement.

As shown in the model, the classroom learning environment factors, except teacher support (TS), course organisation (CO), and innovation in teaching (IT), had a significant impact on student engagement. Of the significant regression paths, peer competition (PC), cooperative learning (CL), and intellectual stimulation (IS) had positive influences on student engagement in activities for analytical understanding (AU), while difficulty of learning (DL) had negative influences on student engagement in AU. CL and IS had positive influences on student engagement in meeting academic challenges (MAC). CL, DL, and IS had positive influences on student interaction with faculty (IF). CL and IS had positive influences on LE (reverse-coded), while student autonomy (SA) and DL had negative influences on LE (reverse-coded). PC, CL, and IS had positive influences on extracurricular engagement (EE), while DL had negative influences on EE. The findings of the significance of peer interaction were in tandem with the findings from the qualitative research, which found peer support played a crucial role in international students' active engagement in learning.

Figure 2 also shows that the campus climate factor of respect for diversity (RD) positively predicted student engagement in AU and LE (reverse-coded). The result, in line with the finding of the qualitative research, suggested the significance of feeling respected in effective learning. The other campus climate factor, general campus atmosphere (GA), had no significant impact on student engagement.

\subsubsection{Student Engagement: Comparing Discipline and Institutional Differences}

Study 1 involved MBBS students only. To extend our understanding, Study 2 compared and analyzed academic engagement among the respondents with different disciplinary backgrounds and at different types of institutions. The ANOVA results (see Table 4) indicated that the survey respondents in life sciences and medical disciplines (LMed) had significantly higher levels of the engagement in AU and EE and significantly higher levels of LE (reverse-coded) than the respondents in arts, 
humanities, and social science disciplines (AHSS) or the respondents in science and engineering disciplines (SEng). The SEng respondents reported higher levels of engagement in AU and EE than the AHSS respondents. The AHSS respondents reported higher levels of LE (reverse-coded) than the SEng respondents. There were no significant discipline differences regarding the respondents' engagement in MAC and IT.

Table 4. Disciplinary and institutional differences in student engagement.

\begin{tabular}{|c|c|c|c|c|c|c|}
\hline Factor & Group & & $\mathbf{N}$ & $\mathbf{M}$ & SD & $F / t$ \\
\hline \multirow{6}{*}{$\mathrm{AU}$} & \multirow{3}{*}{ Discipline } & AHSS & 260 & 3.37 & 0.95 & \multirow{3}{*}{$6.607^{* * *}$} \\
\hline & & SEng & 130 & 3.59 & 1.05 & \\
\hline & & LMed & 899 & 3.64 & 1.11 & \\
\hline & \multirow[b]{2}{*}{ Institution } & DFU & 903 & 3.57 & 1.07 & \multirow[b]{2}{*}{-0.129} \\
\hline & & Non-DFU & 415 & 3.58 & 1.12 & \\
\hline & Discipline $\times$ institution & & & & & 0.210 \\
\hline \multirow{6}{*}{ MAC } & \multirow{3}{*}{ Discipline } & AHSS & 259 & 3.43 & 0.97 & \multirow{3}{*}{2.478} \\
\hline & & SEng & 132 & 3.69 & 1.21 & \\
\hline & & LMed & 890 & 3.54 & 1.16 & \\
\hline & \multirow{2}{*}{ Institution } & DFU & 896 & 3.50 & 1.12 & \multirow{2}{*}{-1.068} \\
\hline & & Non-DFU & 413 & 3.57 & 1.16 & \\
\hline & Discipline $\times$ institution & & & & & 2.545 \\
\hline \multirow{6}{*}{ IF } & \multirow{3}{*}{ Discipline } & AHSS & 265 & 2.96 & 1.00 & \multirow{3}{*}{1.902} \\
\hline & & SEng & 132 & 3.09 & 1.15 & \\
\hline & & LMed & 914 & 2.89 & 1.16 & \\
\hline & \multirow{2}{*}{ Institution } & DFU & 919 & 2.89 & 1.12 & \multirow{2}{*}{-1.795} \\
\hline & & Non-DFU & 420 & 3.01 & 1.16 & \\
\hline & Discipline $\times$ institution & & & & & 0.164 \\
\hline \multirow{6}{*}{ LE } & \multirow{3}{*}{ Discipline } & AHSS & 267 & 4.68 & 0.96 & \multirow{3}{*}{$20.770^{* * *}$} \\
\hline & & SEng & 135 & 4.49 & 1.16 & \\
\hline & & LMed & 894 & 4.98 & 0.97 & \\
\hline & \multirow{2}{*}{ Institution } & DFU & 910 & 4.93 & 0.95 & \multirow{2}{*}{$3.208^{* * *}$} \\
\hline & & Non-DFU & 413 & 4.73 & 1.11 & \\
\hline & Discipline $\times$ institution & & & & & 1.010 \\
\hline \multirow{6}{*}{$\mathrm{EE}$} & \multirow{3}{*}{ Discipline } & AHSS & 256 & 3.22 & 0.98 & \multirow{3}{*}{$14.469^{* * *}$} \\
\hline & & SEng & 133 & 3.61 & 1.21 & \\
\hline & & LMed & 869 & 3.64 & 1.11 & \\
\hline & \multirow{2}{*}{ Institution } & DFU & 881 & 3.56 & 1.08 & \multirow{2}{*}{0.854} \\
\hline & & Non-DFU & 405 & 3.51 & 1.16 & \\
\hline & Discipline $\times$ institution & & & & & 1.211 \\
\hline
\end{tabular}

Note: $1 .{ }^{* * *} P<0.001 ; 2$. DFUs $=$ double-first-class universities, NDFUs $=$ non-double-first-class universities; 3. $\mathrm{AU}=$ participation for analytical understanding, $\mathrm{MAC}=$ meeting academic challenges, $\mathrm{IF}=$ interaction with faculty, $\mathrm{LE}=$ lack of engagement, $\mathrm{EE}=$ extracurricular engagement.

The results of $t$-test showed that the respondents at national elite double-first-class universities reported significantly higher levels of LE (reverse-coded) than the respondents at non-double-first-class universities. No significant institutional difference was found for another four engagement factors. There was no significant interaction effect of discipline and institutional differences in student engagement.

\section{Summary and Discussion}

Both studies pointed to important features of international students' engagement in learning. The survey study showed that the mean value of MAC ranked the second-lowest among those of the five engagement factors, while the least positive responses were to students' interaction with host teachers. The explorative interview study showed that although some interviewees challenged themselves by learning international reference books, most adopted an examination-oriented learning 
approach, i.e., learning mainly by memorization for passing the examinations. The interviews also identified inadequate quality and quantity of teacher-student interactions. All interviewees referred to lecturers' lack of English proficiency as a reason for the weak interaction. Some interviewees stressed lecturers' unapproachability, perceiving lecturers as unwilling to interact with them in teaching.

The survey study showed that the six environmental factors which had significant effects on student engagement could be classified into three groups. The first group involved PC and DL, both of which had double-edged effects on student engagement. DL could promote respondents' interactions with faculty and reduce lack of engagement but also reduce respondents' engagement in extracurricular activities. Similarly, PC could positively enhance students' engagement in analytical understanding, while negatively affecting students' extracurricular engagement. The second group involved SA and $\mathrm{RD}$, both of which had limited influences on student engagement. SA could increase students' lack of engagement, with no significant influences on other engagement factors. RD had only positive influences on students' engagement in analytical understanding and could reduce students' lack of engagement. It had no significant effects on other engagement aspects.

The third group involves CL and IS, both of which had positive influences on most aspects of student engagements. It should be noted that the interview study had also revealed peer collaboration as an important way of learning. The traditional way of teaching, lack of approachability of lecturers, and the sense of being inadequately included or respected pushed the interviewees to turn to their peer groups for support in learning. Lee, Yin, and Zhang [76] found that "the culture-specific nature of teacher-centeredness in Asian region" induced active learning among Hong Kong college students (p.228). The two studies reported in this article revealed learner cooperation as one strong predictor of international undergraduate students' engagement, highlighting the complexity of Chinese classroom cultures within its growingly internationalized HEIs.

The interview study focused on international students in MBBS at a research-centered university. To deepen our understanding, the survey study was designed to examine whether disciplines and institutional differences influenced student engagement and how. There has been no internationally published research focusing on Chinese contexts and exploring how international undergraduate students' academic engagement varies by disciplines and institutions. Specifically, the survey study differentiated the respondents' disciplinary background into three broad types, i.e., SEng, LMed, and AHSS. It revealed that the LMed respondents reported consistently more active engagement in AU, LE (reverse-coded), and EE. The more extended history of the curricula development of MBBS may explain more positive responses among medical students. The results, however, need to be interpreted cautiously. The interview study evidenced insufficient engagement among the MBBS interviewees. The survey results of the less positive responses given by SEng and AHSS respondents might suggest a general lack of active engagement among the respondents across disciplines.

In addition, the survey study revealed less active engagement among SEng majors in AU, LE (reverse-coded), and EE, while no significant discipline differences were found with regard to student engagement in MAC and IT. The nation's generous investment in sciences and engineering may have led to the impressive enhancement of the disciplines' research output [77]. It, however, has not much positively impacted the academic engagement of international students majoring in these disciplines.

Moreover, the survey study did not reveal significant institutional differences in four engagement dimensions, i.e., AU, MAC, IT, and EE. The result suggested that the survey respondents at national key double-first-class universities did not engage more actively in these areas than those at teaching-centered universities. The only exception was LE (reverse-coded). Furthermore, the survey study revealed no significant interaction effect of disciplines and institutions on student engagement. The result suggested that despite their strategic, personnel, and resource advantages, the sciences and engineering at the double first-class universities did not show any advantages over other disciplines at teaching universities with regard to supporting international students' academic engagement. The findings 
were different from those of the research on Chinese domestic students [53,66], which might reflect an overall inadequate engagement of international undergraduate students in Chinese HEIs.

\section{Limitations}

The research reported in this article holds several limitations. First, the sample may not reflect the demographic distribution of the international undergraduate student population in China. Second, Study 1 focused on the interviewees' narration, which may or may not reflect the actuality of learning and teaching. Study 2 classified disciplines into three groups and institutions into two types. Other ways to categorize disciplines and institutions may shed new light on their impact on international student engagement [43]. In addition, Study 1 involved international students in MBBS only, while Study 2 followed a one-time "snapshot" survey design. To further our understanding, we call for annual national surveys and qualitative studies that complement each other. Qualitative research will reveal the nuances of international student engagement. Annual surveys, while providing a bigger picture, will allow for the comparison of student engagement data over consecutive years.

\section{Conclusions}

Rapid international student enrollment expansion has put pressure on Chinese HEIs to assess and monitor the quality of its international education. The pressure is becoming intense following the release of the Standards [36]. This article focused on the academic engagement of international undergraduate students during their studies in China. The discussion was based on the findings of an exploratory qualitative study, following a small group of international undergraduate students at a research university, and large-scale quantitative research involving 1428 international undergraduate students at 34 Chinese HEIs. The qualitative study provided grounds for the survey study, helping to inform the design of the latter. Comparing key findings from the two studies, which involved different groups of learners interacting with different groups of academics in different settings, revealed distinctive, yet common features of international students' engagement. Given the similar challenges faced by international students worldwide [67-72], the research findings contribute to the extended and deepened understanding of international student academic engagement in China and beyond, informing practitioners worldwide of the crucial environment factors that would influence such engagement.

Specifically, both studies showed less than satisfactory levels of student engagement, with a high proportion of the participants being less likely to be actively involved in knowledge construction activities or enriching learning practices. Both studies pointed to international students' significantly inadequate engagement in interaction with the faculty. The qualitative research suggested that the participants' engagement was affected by teachers' heavy reliance on didactic lecturing, hardly interacting with students, and the course administration showing inadequate "sincere empathy" [78] (p.530). The survey results indicated six environmental factors, categorized into three groups, having significant effects on the respondents' engagement. Dissatisfied with teaching, interview participants relied on peer support in learning. Similarly, the survey revealed peer cooperation as one of the two factors strongly predicting the respondents' active engagement in learning. The noteworthy point is that the survey did not find significant institutional differences or significant interaction effects of disciplines and institutions on student engagement.

Studies on international undergraduate students are emerging, but our understanding of these students' academic experience remains limited. This article contributes to the existing literature by analyzing international undergraduate students' academic engagement and environmental factors predicting such engagement. It is of potential significance in the current context in which China's international student education is transforming from "volume increase" to "quality enhancement", as demanded by the national government [37]. The analyses in the article suggest crucial issues for consideration in the discussion of the sustainable development of China's international student 
education. To further our understanding, we call for annual large-scale surveys and a series of qualitative studies that complement each other.

Although focusing on China, the article bears implications for practitioners involved in international student education in a broader range of contexts. First, it is of importance that the evaluation of the international education quality is student- and learning-centered. Compared to the evaluation practices centering on resources, equipment, or quality of teaching, international students' perceptions and their voices are much significant, enabling the understandings of the students' experiences in general and pinpointing the problematic areas for improvement in particular.

Second, both studies reported in this article revealed low levels of academic engagement among international undergraduate students in China. The survey study reported no significant differences with regard to student engagement between research-centered and teaching-centered Chinese universities; nor was there significant interaction effect of disciplines and institutions on student engagement. The nature and extent of international undergraduate students engaging in educational practices are a function of their interactions with the learning environments that host institutions and faculty construct. Hu and Kuh [43] remind us that students' personal characteristics are either unable or very difficult for institutions to change, and therefore the potentially productive approach to enhance student engagement is to change students' perceptions of certain aspects of learning environments. While all HEIs are expected to do so, national elite research-centered universities, given the resources, facilities, and academic strength they enjoy, should play a leading role in transforming the learning environments and supporting international student engagement.

For example, based on the findings reported in this article, it is suggested that faculty members develop competencies to use active teaching methods and techniques which encourage collaborative learning among international students $[57,58]$ and integrate inspiring learning opportunities to support international student development [59], whilst carefully managing peer competition and curricula difficulties to avoid potential adverse effects on engagement. More importantly, universities should encourage faculty and administrators to review the ways they are working with international students. The "transformative", rather than "symbolic", internationalized environments can best encourage international students' engagement [79]. The transformation of classroom and campus climates is by no means easy but remain central to international students' sustainable engagement in host higher education [38,73].

Author Contributions: M.T. and G.L. wrote the paper. H.Y. reviewed and edited the paper. L.L. contributed significantly to the initial analysis of the data. All authors have read and agreed to the published version of the manuscript.

Funding: The research was supported by the National Natural Science Foundation of China Youth Scheme [71804145] and the Social Science Fund of Shaanxi Province [2018Q03].

Conflicts of Interest: The authors declare no conflict of interest.

\section{References}

1. Ministry of Education, China. Statistics of International Students in China in 2018; Department of International Cooperation and Exchanges of the Ministry of Education China: Beijing, China, 2019.

2. Institute of International Education. Project Atlas: Current Infographics. 2019. Available online: https://www. iie.org/en/Research-and-Insights/Project-Atlas/ExploreData/Infographics/2019-Project-Atlas-Infographics (accessed on 12 June 2020).

3. Schulmann, P.; Ye, C. China: Can the world's top source for international students become its leading destination. 2017. Available online: https://wenr.wes.org/2017/08/china-can-the-worlds-top-source-forinternational-students-become-its-leading-destination (accessed on 3 March 2020).

4. Tian, M.; Dervin, F.; Lu, G. Academic Experiences of International Students in Chinese Higher Education; Routledge: London, UK, 2020.

5. Bae, Y.; Han, S. Academic Engagement and Learning Outcomes of the Student Experience in the Research University: Construct Validation of the Instrument. Educ. Sci. Theory Pract. 2019, 19, 49-64. 
6. Ding, X. Exploring the experiences of international students in China. J. Stud. Int. Educ. 2016, 20, 319-338. [CrossRef]

7. Haugen, H. China's recruitment of African university students: Policy efficacy and unintended outcomes. Glob. Soc. Educ. 2013, 11, 315-334. [CrossRef]

8. Wen, W.; Hu, D. The emergence of a regional education hub: Rationales of international students' choice of China as the study destination. J. Stud. Int. Educ. 2019, 23, 303-325. [CrossRef]

9. Tian, M.; Lowe, J. Intercultural identity and intercultural experiences of American students in China. J. Stud. Int. Educ. 2014, 18, 281-297. [CrossRef]

10. Akhtar, N.; Pratt, C.; Shan, B. Factors in the cross-cultural adaptation of African students in Chinese universities. J. Res. Int. Educ. 2015, 14, 98-113. [CrossRef]

11. Macready, C.; Tucker, C. Who Goes Where and Why? An Overview and Analysis of Global Education Mobility; Institute of International Education: New York, NY, USA, 2011.

12. Ministry of Education, China. A Brief Introduction to International Student Education in China. 2015. Available online: http://old.moe.gov.cn//publicfiles/business/htmlfiles/moe/moe_279/200409/375.html (accessed on 11 September 2019).

13. Ministry of Education, China. Studying in China Scheme. 2010. Available online: http://202.205.177.9/edoas/ website18/52/info1285655371911352.html (accessed on 11 September 2019).

14. Ministry of Education, China. Statistics of International Students in China in 2010; Department of International Cooperation and Exchanges of the Ministry of Education China: Beijing, China, 2011.

15. Ministry of Education, China. Statistics of International Students in China in 2001; Department of International Cooperation and Exchanges of the Ministry of Education China: Beijing, China, 2002.

16. Ministry of Education, China. Statistics of International Students in China in 2002; Department of International Cooperation and Exchanges of the Ministry of Education China: Beijing, China, 2003.

17. Ministry of Education, China. Statistics of International Students in China in 2003; Department of International Cooperation and Exchanges of the Ministry of Education China: Beijing, China, 2004.

18. Ministry of Education, China. Statistics of International Students in China in 2004; Department of International Cooperation and Exchanges of the Ministry of Education China: Beijing, China, 2005.

19. Ministry of Education, China. Statistics of International Students in China in 2005; Department of International Cooperation and Exchanges of the Ministry of Education China: Beijing, China, 2006.

20. Ministry of Education, China. Statistics of International Students in China in 2006; Department of International Cooperation and Exchanges of the Ministry of Education China: Beijing, China, 2007.

21. Ministry of Education, China. Statistics of International Students in China in 2007; Department of International Cooperation and Exchanges of the Ministry of Education China: Beijing, China, 2008.

22. Ministry of Education, China. Statistics of International Students in China in 2008; Department of International Cooperation and Exchanges of the Ministry of Education China: Beijing, China, 2009.

23. Ministry of Education, China. Statistics of International Students in China in 2009; Department of International Cooperation and Exchanges of the Ministry of Education China: Beijing, China, 2010.

24. Ministry of Education, China. Statistics of International Students in China in 2011; Department of International Cooperation and Exchanges of the Ministry of Education China: Beijing, China, 2012.

25. Ministry of Education, China. Statistics of International Students in China in 2012; Department of International Cooperation and Exchanges of the Ministry of Education China: Beijing, China, 2013.

26. Ministry of Education, China. Statistics of International Students in China in 2013; Department of International Cooperation and Exchanges of the Ministry of Education China: Beijing, China, 2014.

27. Ministry of Education, China. Statistics of International Students in China in 2014; Department of International Cooperation and Exchanges of the Ministry of Education China: Beijing, China, 2015.

28. Ministry of Education, China. Statistics of International Students in China in 2015; Department of International Cooperation and Exchanges of the Ministry of Education China: Beijing, China, 2016.

29. Ministry of Education, China. Statistics of International Students in China in 2016; Department of International Cooperation and Exchanges of the Ministry of Education China: Beijing, China, 2017.

30. Ministry of Education, China. Statistics of International Students in China in 2017; Department of International Cooperation and Exchanges of the Ministry of Education China: Beijing, China, 2018. 
31. Ministry of Education, China. Announcement of the lists of world-class construction universities and first-class construction disciplines. 2017. Available online: http://www.moe.gov.cn/srcsite/A22/moe_843/ 201709/t20170921_314942.html (accessed on 12 February 2019).

32. State Council, China. An Overall Plan to Promote the Development of World-Class Universities and World-Class Disciplines. 2015. Available online: http://www.gov.cn/zhengce/content/2015-11/05/content_ 10269.html (accessed on 26 April 2016).

33. Shanghai ranking.com. Academic Ranking of World Universities 2019. 2019. Available online: http: //www.shanghairanking.com/ARWU2019.html (accessed on 3 March 2020).

34. Shanghai ranking.com. Global Ranking of Academic Subject 2019. 2019. Available online: http://www. shanghairanking.com/Shanghairanking-Subject-Rankings/index.html (accessed on 3 March 2020).

35. Liu, X. The "Double First-Class" initiative under top-level design. ECNU Rev. Educ. 2018, 1, 147-152. [CrossRef]

36. Ministry of Education, China. Quality Standards for International Student Higher Education in China (trial version). 2018. Available online: http://www.moe.gov.cn/srcsite/A20/moe_850/201810/t20181012_ 351302.html (accessed on 3 February 2019).

37. Ministry of Education, China. Quality Goes First to Realise the Connotative Development of International Student Education. 2019. Available online: http://www.moe.gov.cn/jyb_xwfb/s271/201907/t20190719_391532. html (accessed on 3 March 2019).

38. Kahu, E.R. Framing student engagement in higher education. Stud. High. Educ. 2011, 38, 758-773. [CrossRef]

39. Pace, C.R. Measuring the quality of student effort. Curr. Issues High. Educ. 1980, 2, 10-16.

40. Astin, A.W. Student involvement: A developmental theory for higher education. J. Coll. Stud. Dev. 1984, 25, 297-308.

41. Tinto, V. Leaving College: Rethinking the Causes and Cures of Student Attrition; University of Chicago Press: Chicago, IL, USA, 1987.

42. Krause, K.L.; Coates, H. Students' engagement in first-year university. Assess. Eval. High. Educ. 2008, 33, 493-505. [CrossRef]

43. Hu, S.; Kuh, G.D. Being (dis) engaged in educationally purposeful activities: The influences of student and institutional characteristics. Res. High. Educ. 2002, 43, 555-575. [CrossRef]

44. Kuh, G.D. What we're learning about student engagement from NSSE: Benchmarks for effective educational practices. Change 2003, 35, 24-32. [CrossRef]

45. Fredricks, J.; Blumenfeld, P.; Paris, A. School engagement: Potential of the concept, state of the evidence. Rev. Educ. Res. 2004, 74, 59-109. [CrossRef]

46. Kuh, G.D.; Cruce, T.M.; Shoup, R.; Kinzie, J.; Gonyea, R.M. Unmasking the effects of student engagement on first-year college grades and persistence. J. High. Educ. 2008, 79, 540-563. [CrossRef]

47. Carini, R.M.; Kuh, G.D.; Klein, S.P. Student engagement and student learning: Testing the linkages. Res. High. Educ. 2006, 47, 1-32. [CrossRef]

48. Zhao, C.M.; Kuh, G.D. Adding value: Learning communities and student engagement. Res. High. Educ. 2004, 45, 115-138. [CrossRef]

49. Coates, H. The value of student engagement for higher education quality assurance. Qual. High. Educ. 2005, 11, 25-36. [CrossRef]

50. Kuh, G.D. The national survey of student engagement: Conceptual and empirical foundations. New Dir. Inst. Res. 2009, 141, 5-20. [CrossRef]

51. Ross, H.; Cen, Y.; Zhou, Z. Assessing student engagement in China: Responding to local and global discourse on raising educational quality. Curr. Issues Comp. Educ. 2011, 14, 24-37.

52. Shi, J.H. Governing the quality: Current and future development of the student survey in China. China High. Educ. Res. 2016, 2, 37-41.

53. Yin, H.; Wang, W. Undergraduate students' motivation and engagement in China: An exploratory study. Assess. Eval. High. Educ. 2016, 41, 601-621. [CrossRef]

54. Lim, C.T.D.; Fraser, B.J. Learning environments research in English classrooms. Learn. Environ. Res. 2018, 21, 433-449. [CrossRef]

55. Coates, H. A model of online and general campus-based student engagement. Assess. Eval. High. Educ. 2007, 32, 121-141. [CrossRef] 
56. Lei, H.; Cui, Y.; Chiu, M.M. The relationship between teacher support and students' academic emotions: A meta-analysis. Front. Psychol. 2018, 8, 2288. [CrossRef]

57. Ahlfeldt, S.; Mehta, S.; Sellnow, T. Measurement and analysis of student engagement in university classes where varying levels of PBL methods of instruction are in use. High. Educ. Res. Dev. 2005, 24, 5-20. [CrossRef]

58. Almarghani, E.M.; Mijatovic, I. Factors affecting student engagement in HEIs-it is all about good teaching. Teach. High. Educ. 2017, 22, 940-956. [CrossRef]

59. Umbach, P.D.; Wawrzynski, M.R. Faculty do matter: The role of college faculty in student learning and engagement. Res. High. Educ. 2005, 46, 153-184. [CrossRef]

60. Matthews, K.E.; Andrews, V.; Adams, P. Social learning spaces and student engagement. High. Educ. Res. Dev. 2011, 30, 105-120. [CrossRef]

61. Brint, S.; Cantwell, A.M.; Saxena, P. Disciplinary categories, majors, and undergraduate academic experiences. Res. High. Educ. 2012, 53, 1-25. [CrossRef]

62. Gainen, J. Barriers to success in quantitative gatekeeper courses. New Dir. Teach. Learn. 1995, 61, 5-14. [CrossRef]

63. Johnson, V.E. Grade Inflation: A Crisis in College Education; Springer: New York, NY, USA, 2003.

64. Arcidiacono, P. Ability sorting and the returns to college major. J. Econom. 2004, 121, 343-375. [CrossRef]

65. Shi, J.H.; Wen, W. Tsinghua University undergraduate education survey report 2010. Tsinghua J. Educ. 2012, 33, 4-16.

66. Shi, J.H.; Tu, D.; Wang, S.; Lv, Z.; Xie, M.; Zhao, L. Annual report of national education survey 2009. Tsinghua J. Educ. 2011, 32, 9-32.

67. Leask, B. Using formal and informal curricula to improve interactions between home and international students. J. Stud. Int. Educ. 2009, 13, 205-221. [CrossRef]

68. Tian, M.; Lowe, J. The Role of feedback in cross-cultural learning: A case study of Chinese taught postgraduate students in a UK university. Assess. Eval. High. Educ. 2013, 38, 580-598. [CrossRef]

69. Volet, S.E.; Ang, G. Culturally mixed groups on international campuses: An opportunity for intercultural learning. High. Educ. Res. Dev. 1998, 17, 5-23. [CrossRef]

70. Benzie, H.J. Graduating as a "native speaker": International students and English language proficiency in higher education. High. Educ. Res. Dev. 2010, 29, 447-459. [CrossRef]

71. Guo, S.; Chase, M. Internationalisation of higher education: Integrating international students into Canadian academic environment. Teach. High. Educ. 2011, 16, 305-318. [CrossRef]

72. Tian, M.; Lowe, J. Existentialist internationalisation and the Chinese student experience in English universities. Compare 2009, 39, 659-676. [CrossRef]

73. Mann, S.J. Alternative perspectives on the student experience: Alienation and engagement. Stud. High. Educ. 2001, 26, 7-19. [CrossRef]

74. Edelstein, R. Globalization and Student Learning; Research \& Occasional Paper Series: CSHE. 6.14. Center for Studies in Higher Education, University of California: Berkeley, CA, USA, 2014.

75. Yin, H.; Lu, G. Development and validation of an instrument for assessing mathematics classroom environment in tertiary institutions. Asia-Pac. Educ. Res. 2014, 23, 655-669. [CrossRef]

76. Lee, J.C.K.; Yin, H.; Zhang, Z. Exploring the influence of the classroom environment on students' motivation and self-regulated learning in Hong Kong. Asia-Pac. Educ. Res. 2009, 18, 219-232. [CrossRef]

77. Institute of Scientific and Technical Information of China. 2019 Statistics of Chinese Science and Technology Articles. 2019. Available online: http://www.gov.cn/shuju/2019-11/20/content_5453698.htm (accessed on 20 February 2020).

78. Marx, S.; Pray, L. Living and learning in Mexico: Developing empathy for English language learners through study abroad. Race Ethn. Educ. 2011, 14, 507-535. [CrossRef]

79. Turner, Y.; Robson, S. Internationalising the University; Continuum: London, UK, 2008.

(C) 2020 by the authors. Licensee MDPI, Basel, Switzerland. This article is an open access article distributed under the terms and conditions of the Creative Commons Attribution (CC BY) license (http://creativecommons.org/licenses/by/4.0/). 